\title{
Shortening in the Tp-e/QTc ratio after angioplasty in patients with acute coronary syndrome
}

\author{
Acortamiento en la relación Tp-f/QTc tras angioplastia en pacientes con síndrome \\ isquémico coronario agudo
}

\author{
Rodolfo M. Román-Guzmán ${ }^{*}$, Jorge A. Joya-Harrison', Claudia A. Navarrete-López1, \\ Arturo M. Cadena-Payton', Víctor Segura-Ibarra ${ }^{3}$, and Salvador B. Valdovinos-Chávez \\ ${ }^{1}$ Department of Internal Medicine, Hospital San José Tec Salud; ${ }^{2}$ Institute of Cardiology, Centro Médico Zambrano Hellion, School of Medicine, \\ Tecnológico de Monterrey; ${ }^{3}$ School of Engineering and Sciences, Tecnológico de Monterrey. Monterrey, Nuevo León, Mexico
}

\begin{abstract}
Objective: Transmural dispersion of repolarization (TDR) is a risk factor for death in patients with acute coronary syndrome (ACS). To know the effect of angioplasty on TDR, the Tp-e/QTC ratio was studied in patients with ACS undergoing angioplasty. Methods: An observational, retrospective, and descriptive study was designed. One hundred fifty patients $(n=150)$ with diagnosis of $z$ were included in the study. The initial Tp-e/QTc ratio was assessed and then its post-angioplasty shortening was evaluated. As a secondary objective, we compared the association of these Tp-e/QTc ratio changes with cardiovascular mortality and cardiovascular adverse events. Results: The average in the initial Tp-e/QTc ratio was 0.2529 , while post-angioplasty was 0.2397 . Through a Wilcoxon rage test, a significant decrease in the Tp-e/QTc ratio after angioplasty was observed, with a $Z$ value of -2.051 and $p<0.04$. In the secondary analysis, it was found that a Tp-e/QTC $\geq 0.29$ post-angioplasty is a risk factor for presenting the following adverse events: in-hospital death (7.4 vs. $0 \% ; p<0.003)$, new ACS in 1-year follow-up (25.9 vs. 18.5\%; $p<0.006)$, and reintervention in 1-year follow-up (29.6 vs. 15\%; $p<0.002)$. Conclusions: There is a significant shortening in the Tp-e/QTc ratio post-angioplasty in patients with ACS. This measure of TDR can serve as a predictor of in-hospital death, cardiovascular events, and 1-year reintervention in patients with ACS treated initially by angioplasty.
\end{abstract}

Key words: Acute coronary syndrome. Transmural dispersion of repolarization. Tp-e. Tp-f/QT.

\section{Resumen}

Objetivo: La dispersión transmural de la repolarización ventricular (DTMRV) es un factor de riesgo para muerte en pacientes con síndrome isquémico coronario agudo (SICA). Con el objetivo de conocer el efecto de la realización de angioplastia sobre la DTMRV, se estudió la relación Tp-f/QTc en pacientes con SICA sometidos a angioplastia. Método: Se diseñó un estudio observacional, retrospectivo y descriptivo. Se incluyeron 150 pacientes $(N=150)$ con diagnóstico de SICA. Se valoró la relación Tp-f/QTc inicial y se evaluó su acortamiento posangioplastia. Como objetivo secundario, se comparó la asociación de dichos cambios en la relación Tp-f/QTc con la mortalidad cardiovascular y los eventos adversos cardiovasculares. Resultados: El promedio en la relación Tp-f/QTc inicial fue de 0.2529, mientras que posangioplastia fue de 0.2397. Por

\section{Correspondence:}

*Rodolfo M. Román-Guzmán

E-mail: rodolfo.roman.guzman @gmail.com
Available online: 02-03-2021 Arch Cardiol Mex (Eng). 2020;90(4):416-430 www.archivoscardiologia.com 2604-7063 / @ 2020 Instituto Nacional de Cardiología Ignacio Chávez. Published by Permanyer. This is an open access article under the CC BY-NC-ND license (http://creativecommons.org/licenses/by-nc-nd/4.0/). 
medio de prueba de rangos de Wilcoxon se evidenció un descenso significativo en la relación Tp-f/QTc posteriora la angio plastia, con un valor $Z$ de -2.051 y una $p<0.04$. En el análisis secundario se encontró que una $T p-f / Q T c \geq 0.29$ posangio plastia es factor de riesgo para presentación de los siguientes eventos adversos: muerte intrahospitalaria (7.4 vs 0\%; $p<0.003)$, nuevo SICA en seguimiento a 1 año (25.9 vs. $18.5 \%$; $p$ < 0.006) y reintervención en seguimiento a 1 año (29.6 vs. $15.0 \% ; p<0.002$ ). Conclusiones: Existe un acortamiento significativo en la relación Tp-f/QTc posangioplastia en pacientes con SICA. Esta medida de la DTMRV puede servir como un predictor de muerte intrahospitalaria, eventos cardiovascu lares y reintervención a 1 año en pacientes con SICA tratados con angioplastia.

Palabras clave: DTMRV. SICA. Tp-f. Tp-f/QT.

\section{Introduction}

According to figures of the National Institute of Statistics and Geography, in 2016, heart diseases were the leading cause of death in Mexico. Seventy-one percent had ischemic heart disease as origin, which represents $14 \%$ of total deaths in our country ${ }^{1}$.

The leading cause of sudden cardiac death in patients with ischemic heart disease is malignant ventricular arrhythmias. According to the study by Bayés de Luna et al. ${ }^{2}$, approximately $80 \%$ of cases of sudden cardiac death are the result of tachyarrhythmia, either ventricular tachycardia or ventricular fibrillation, and only $20 \%$ are due to bradyarrhythmias such as idioventricular rhythms, atrioventricular blocks, or asystole. Different parameters have been proposed as predictors of malignant ventricular arrhythmias, but none by itself has been shown to have sufficient sensitivity and specificity to predict this devastating event.

Since the 1990s, attention has been paid to transmural dispersion of ventricular repolarization (TDVR) as a risk factor for sudden cardiac death, with special focus on the QTC interval. More recently, the interval comprised from peak to end of the T-wave (Tp-e) and the Tp-e/QTc ratio have been studied as TDVR indices.

T-wave begins when the epicardial action potential plateau disperses from mid-myocardial cells (M region). While the epicardium starts its repolarization, the voltage gradient between the epicardium and the $M$ region generates the $T$ wave ascending end. The voltage gradient between the $\mathrm{M}$ region and the epicardium reaches a peak when the epicardium is entirely repolarized; this marks the T-wave peak. At the other end of the ventricular wall, the endocardial plateau moves away from that of $\mathrm{M}$ cells, generating an opposing voltage gradient and the corresponding current that limits $T$ wave amplitude and contributes to the initial part of its descending end. This way, the voltage gradient between the endocardium and the $M$ region reaches a peak when the endocardium is entirely repolarized. Subsequently, the gradient continues to decline as $\mathrm{M}$ cells conclude their repolarization. Thus, the end of $T$ wave represents the extinction of the gradient when $M$ cells are completely repolarized. Therefore, we can say that $\mathrm{M}$ cells action potential determines the QT-interval ${ }^{3}$ (Fig. 1).

When the T wave is positive, the epicardial region is the first to be repolarized, and $\mathrm{M}$ cells will be the last to do it. Epicardial potential complete repolarization coincides with $T$ wave peak, and $M$ cells repolarization conclusion, with its end. This interval between T-wave peak and its end is known as the Tp-e interval, and represents a TDVR index ${ }^{4}$.

Since the 1990s, attention was paid to TDVR as a risk factor for sudden cardiac death. Some studies have evaluated the QTC interval length in different pathologies, such as systemic arterial hypertension ${ }^{5}$, hypertrophic cardiomyopathy, long QT syndrome, and even acute myocardial infarction ${ }^{6}$. However, the studies conducted by Antzelevitch ${ }^{4}$ arrived to the conclusion that Tp-e constitutes a more faithful reflection of TDVR, and therefore a better arrhythmogenic substrate predictor.

However, to this day, as body weight increases, a linear QT-interval increase that is accompanied by a parallel Tp-e increase is known to exist. In addition, as heart rate increases from 60 to 100 beats $/ \mathrm{min}$, Tp-e linearly decreases from 40 to $100 \mathrm{~ms}^{7}$. However, the relationship between both these electrocardiographic intervals has been studied and the conclusion has been reached that the Tp-e/QT ratio remains relatively constant with the minimum range of 0.15 to 0.25 , which makes it a potentially predictive electrocardiographic measurement to stratify the risk of malignant ventricular arrhythmias or their relapses ${ }^{8}$.

In a study published by Erikssen et al. ${ }^{9}$ in 2012, the terminal part of the QT interval was evaluated, that is, the Tp-e interval, as a predictor of mortality subsequent to acute myocardial infarction. These authors 


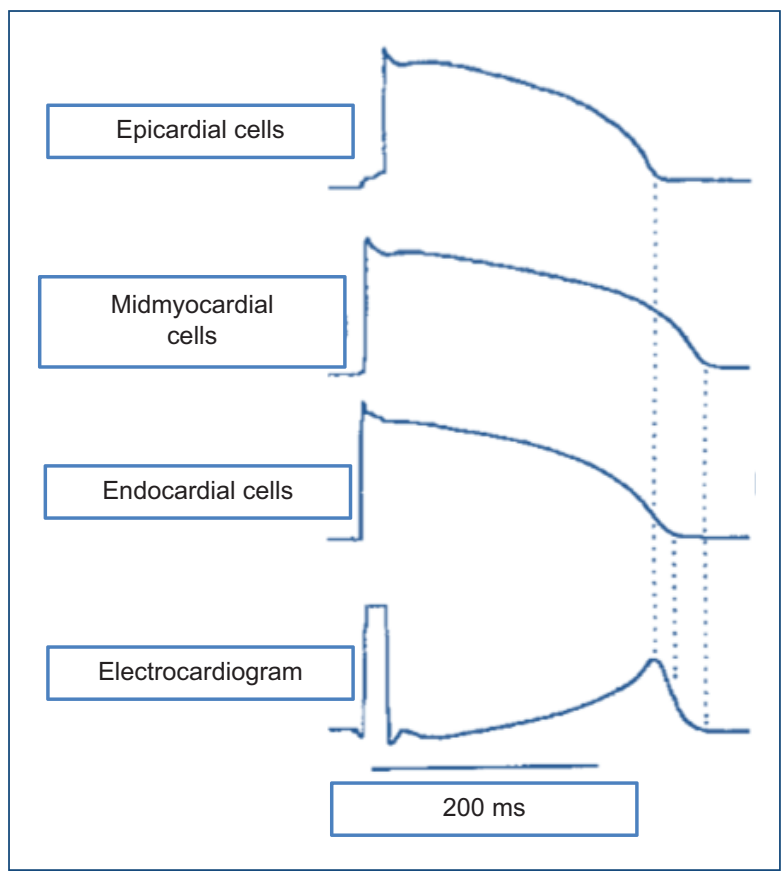

Figure 1. Graphical representation of epicardial, midmyocardial, and endocardial cells electrophysiological profiles.

prospectively evaluated the Tp-e interval in 1359/1385 $(98.2 \%)$ consecutive patients with acute ST-segment elevation myocardial infarction (STEMI) $(n=525)$ or non-STEMI (NSTEMI) $(n=859)$ admitted to a coronary unit of the University of Oslo Hospital, in Norway. They found a significant correlation between $\mathrm{Tp}$-e duration and age, heart rate, left ventricular ejection fraction, creatinine, trivascular coronary artery disease, history of acute myocardial infarction, and QRS and QT duration. Within the 1.3-year follow-up period, 109 patients $(7.9 \%)$ died, 25 of them due to arrhythmia, 45 had cardiac death unrelated to arrhythmia, and 39 died for other non-cardiac causes. The V2 lead showed the longest Tp-e interval in $86 \%$ of cases. Long Tp-e was a strong predictor of mortality risk, and prevailed as such after the performance of a Cox multivariate analysis, with a relative risk (RR) of 1.5 (95\% confidence interval [Cl]: 1.3-1.7). Tp-e was particularly a good predictor of the risk for malignant ventricular arrhythmias, with a RR of $1.6(95 \% \mathrm{Cl}: 1.2-2.1)$. The findings were similar in STEMI and NSTEMI.

Similarly, in 2014, the same University of Oslo group ${ }^{10}$ published a prospective study that assessed 76 patients with a history of acute myocardial infarction who underwent implantable cardioverter-defibrillator insertion. Baseline electrocardiogram (ECG) and follow-up period events were recorded, and episodes of ventricular arrhythmias requiring antitachycardia therapy or defibrillator shock discharge were evaluated. Within a 3.5-year follow-up period, $47 \%$ of the patients had arrhythmias. Tp-e interval was longer in patients who had ventricular arrhythmias than in those who did not (116 \pm 26 vs. $102 \pm 20 \mathrm{~ms} ; p=0.01)$.

In 2012, Zhao et al..$^{11}$ published a study of 338 patients with STEMI that assessed the association between Tp-e/QT ratio and prognosis in patients undergoing percutaneous coronary intervention. These researchers found that the Tp-e/QT ratio was correlated with both short- and long-term prognosis. Of the 388 patients included in the study, 115 (34\%) had a Tp-e/QT $\geq 0.29$. This group of patients with Tp-e/QT $\geq 0.29$ showed higher in-hospital mortality (21.9 vs. $15.3 \%$; $p<0.001)$ and a higher number of cardiovascular adverse events (48.1 vs. $15.3 \% ; p<0.005)$. After discharge, a Tp-e/QT ratio $\geq 0.29$ prevailed as a predictor of all-cause mortality (35.5 vs. $5.2 \% ; p<0.001$ ) and cardiac death (32.3 vs. $2.6 \% ; p<0.001)$.

The purpose of this article is to study the behavior of TDRV in patients with post-angioplasty acute coronary ischemic syndrome (ACIS), and it is the first of its kind to be developed in Mexico.

\section{Methods}

With the purpose to know the effect of angioplasty on the Tp-e/QTc ratio in patients with ACIS, an observational, retrospective study was designed, which included a descriptive analysis of the association of said electrocardiographic changes and the occurrence of adverse events. One-hundred and fifty patients older than18 years $(n=150)$ who attended with an ACIS diagnosis and underwent angioplasty at San José and Zambrano Hellion Tec Salud hospitals, in the period comprised between January 1, 2014 and December 31, 2017, were included, with the QTc and Tp-e intervals, and Tp-e/QTc ratio on their baseline ECG being assessed.

Tp-e/QTc ratio post-angioplasty shortening and its association with mortality and adverse events occurrence were assessed during hospital stay and in follow-up at 1 year. In-hospital morbidity and mortality due to the following events was considered: cardiogenic shock, in-hospital arrhythmia, acute heart failure, in-hospital death, malignant ventricular arrhythmias (both ventricular fibrillation and ventricular tachycardia) and asystole requiring cardiopulmonary resuscitation. 
At 1-year follow-up, re-intervention, new ACIS, and all-cause mortality were assessed.

Standardized 12-lead ECGs obtained at $25 \mathrm{~mm} / \mathrm{s}$ was considered for analysis. The pre-angioplasty ECG assessed for each case corresponded to the one that was carried out before angioplasty. In those cases where the intervention was primary, it corresponded to the ECG obtained at the time of patient arrival to the emergency room. In those cases where early angioplasty was performed, the last ECG obtained before angioplasty was considered. The post-angioplasty ECG considered for analysis after the intervention corresponded to the ECG obtained on the immediate day after angioplasty.

The investigator in charge of ECG review received training under the supervision of a cardiologist specialized in electrophysiology before his/her participation in the study. In patients with STEMI, Tp-e was evaluated in the leads corresponding to the territory of the compromised vessel, with the lead with the highest $\mathrm{J}$ point elevation being considered for the measurement.

In patients with STEMI and unstable angina, the V2 or V5 lead was assessed, according to the researcher's appreciative criterion. The method used for Tp-e measurement was the "tail method", which consists of the measurement of T-wave highest peak interval to the point where the slope of $T$ wave descending branch crosses the isoelectric baseline. QT interval was measured from the beginning of the QRS complex to the point where the tangent of T-wave descending branch maximum slope crosses the isoelectric baseline. Subsequently, consistently with other research groups, a correction was made to obtain the QTC according to $\mathrm{Ba}$ zett's formula: $Q T c=Q T \sqrt{ }(R R)$. Finally, a fractional calculation was carried out to obtain Tp-e/QTc ratio definitive value.

For data obtainment, medical records of the hospitals (Laserfiche $^{\circledR}$ ) and outpatient clinics were used (Alert ${ }^{\circledR}$ and ISSSTELEON). For statistical analysis, the SPSS Statistics ${ }^{\circledR}$ system, version 25, Microsoft $^{\circledR}$ Excel $^{\circledR}$ for Windows 2011, version 14.4.2 (14509), and Microsoft ${ }^{\circledR}$ Power Point ${ }^{\circledR}$ for Mac 2011, version 14.4.2 (140509), were used.

Means and standard deviations were used for continuous and discrete quantitative variables, and for categorical variables, frequencies or percentages were employed. For abnormally distributed quantitative variables, medians and interquartile ranges were used.

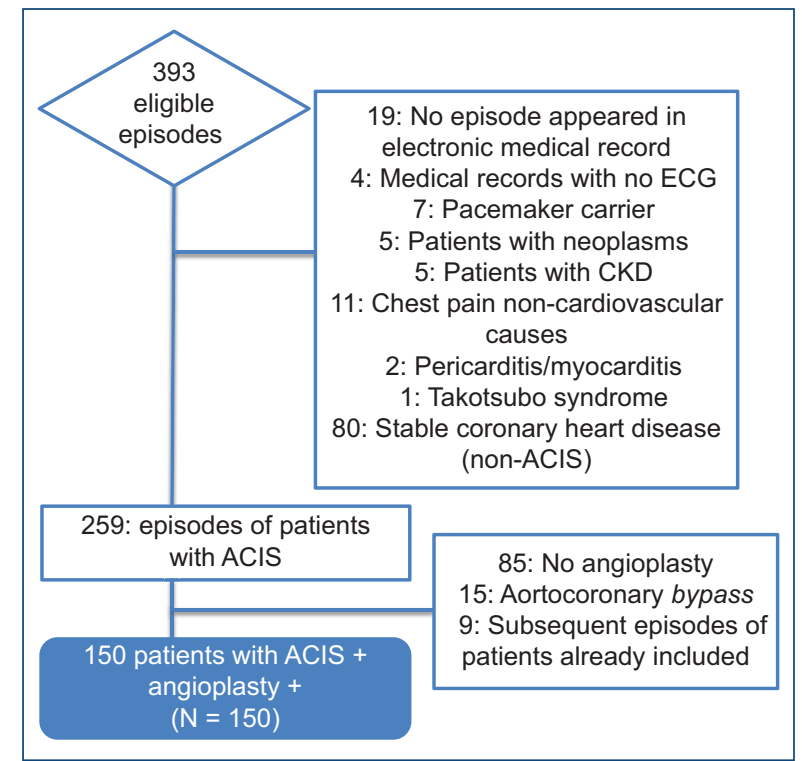

Figure 2. Patient selection based on inclusion and exclusion criteria. ACIS: acute coronary ischemic syndrome; CKD: chronic kidney disease; ECG: electrocardiogram.

The Chi-square test and Student's t-test (in cases of normal distribution) were used for qualitative variables, or Wilcoxon signed-rank test (in cases of abnormal distribution) for quantitative variables. A $95 \% \mathrm{Cl}$ was determined, with a two-sided $p \leq 0.05$ for statistically significant values.

\section{Results}

After reviewing the Tec Salud System Cardiology Censuses, 393 eligible episodes were obtained, corresponding to patients registered due to chest pain who attended the emergency units of San José and Zambrano Hellion Tec Salud hospitals, in the period comprised from January 1, 2014 to December 31, 2017. Following the inclusion and exclusion criteria, 243 episodes were discarded, thus resulting in a total of 150 patients. Figure 2 shows a flow chart depicting phase 2 patients and ECGs collection selection and exclusion process.

In the studied sample (Table 1), average age was $61.6 \pm 11.44$ years; $90.7 \%$ of patients were males. The concomitant conditions that most prevailed were the following: arterial hypertension, present in $46.7 \%$ of participants; smoking, in 40.7\%; type 2 diabetes mellitus, in $34 \%$; and dyslipidemia, in $30 \%$. Only $23.3 \%$ of patients had a history of ischemic heart disease, while 
Table 1. Demographic characteristics, type of acute coronary ischemic syndrome, and affected vessel

\begin{tabular}{|l|c|c|}
\hline Characteristic & \multicolumn{2}{|c|}{ Observed frequency } \\
\hline Age & \multicolumn{2}{|c|}{$61.6 \pm 11.44$} \\
\hline & $\mathbf{n}$ & $\%$ \\
\hline Gender & & \\
Males & 136 & 90.7 \\
\hline Females & 14 & 9.3 \\
\hline Comorbidity & & \\
\hline SAH & 70 & 46.7 \\
DM2 & 51 & 34 \\
Dyslipidemia & 45 & 30 \\
\hline Smoking & 61 & 40.7 \\
Ischemic heart disease & 35 & 23.3 \\
Heart failure & 6 & 4 \\
\hline Type of ACIS & & \\
Unstable angina & 18 & 12 \\
NSTEMI & 59 & 39.3 \\
STEMI & 73 & 48.7 \\
\hline Affected vessel & & \\
RC & & 27.3 \\
AD & 41 & 40.7 \\
Cx & 61 & 10.7 \\
AD + RC & 16 & 6.7 \\
Cx + AD & 10 & 5.3 \\
Cx + RC & 8 & \\
Trivascular disease & 9 & \\
& 5 & \\
\hline
\end{tabular}

ACIS: acute coronary ischemic syndrome; $A D$ : anterior descending coronary artery; Cx: circumflex artery; DM2: type 2 diabetes mellitus; NSTEMI: non-ST segment elevation acute myocardial infarction; RC: right coronary artery; SAH: systemic arterial hypertension; STEMI: ST-segment elevation acute myocardial infarction.

a minimal percentage $(4 \%)$ had a history of heart failure.

One-hundred percent of the studied patients underwent coronary angioplasty during hospitalization, but only $26.6 \%$ of them underwent emergency angioplasty. In these cases, door-to-needle shortest time was $5 \mathrm{~min}$, with a maximum of $147 \mathrm{~min}$ and a mean of $50.38 \pm 32.5$ min. On the other hand, door-to-balloon shortest time was $14 \mathrm{~min}$, with a maximum of $172 \mathrm{~min}$ and a mean of $71.4 \pm 35.27 \mathrm{~min}$.

There were $48.7 \%$ of cases that corresponded to STEMI, $39.3 \%$ were NSTEMI and there were $12 \%$ of unstable angina. In $40.7 \%$ of cases, the anterior descending artery was the most affected vessel, followed by the right coronary artery with $27.3 \%$; in $18 \%$ of cases, more than one vessel was affected.

Average Tp-e/QTc ratio on baseline ECG was 0.2529 \pm 0.0697 , while in the post-angioplasty ECG, it was $0.2397 \pm 0.07200$.
The Kolmogorov-Smirnov test was performed to assess Tp-e/QTc ratio shortening distribution, with a Z-value of 0.078 being found ( $p=0.03$ ), which corroborated that distribution was abnormal; therefore, the Wilcoxon signed-rank test was carried out, and it was concluded that, after angioplasty, there was a significant decrease in the Tp-e/QTc ratio, with a Z-value of -2.051 $(p<0.04)$, thus approving the hypothesis that, after angioplasty, a shortening of the Tp-e/QTc ratio is actually experienced.

For the study of adverse events, both occurring during the procedure and after the intervention, a univariate analysis was carried out with the Chi-square test, with a Tp-e/QTc ratio $\geq 0.25$ being established as the cutoff point for assessing it as a TDVR measurement, which corresponds to the value previously described by Gupta et al. ${ }^{8}$ in their study. In addition, a similar analysis was carried with a cutoff point $\geq 0.29$, based on the aforementioned findings of Zhao et al. ${ }^{11}$.

In the case of peri-procedural events, none was shown to have a statistically significant relationship with a Tp-e/QTc ratio $\geq 0.25$ (Table 2). However, when a Tp-e/QTc ratio $\geq 0.29$ was considered, a statistically significant difference was found for the occurrence of events during the procedure (22.72 vs. $9.43 \%$; $\mathrm{p}<0.029$ ). In addition, the type of observed arrhythmia appears to have a relationship with the degree of TDVR (Table 3).

For the cause-effect analysis corresponding to the degree of TDRV after angioplasty, the occurrence of in-hospital events, as well as at patient follow-up 1 year after the onset of the initial ACIS event, was assessed, similarly as it was done for pre-angioplasty events, using the Chi-square test. A Tp-e/QTc ratio $\geq 0.25$ was found to have statistical significance on the Chi-square test for ACIS reoperation at 1 year of follow-up (25.9 vs. $12.9 \% ; p<0.019$ ), and also for the occurrence of any cardiovascular event at 1 year (31.4 vs. $16.1 \% ; p<0.030$ ). When a cutoff point $\geq 0.29$ was established for the Tp-e/QTc ratio, statistical significance was found for the occurrence of the following side effects: in-hospital death (7.4 vs. $0 \% ; p<0.003)$, new ACIS at 1-year follow-up (25.9 vs. $18.5 \%$; $p<0.006$ ), reoperation (29.6 vs. $15.0 \% ; p<0.002$ ), and occurrence of any cardiovascular event at 1 year (37 vs. $18.3 \% ; p<0.033$ ). These results are summarized in tables 4 and 5 .

Based on the aforementioned findings, logistic regression was used for the analysis of the events that were significant in the univariate analysis. However, no 
Table 2. Peri-procedural events. Univariate analysis for a Tp-e/QTc ratio $\geq 25$

\begin{tabular}{|l|c|c|c|c|}
\hline Variable & $\begin{array}{c}\text { Total patients } \\
\mathbf{n = 1 5 0}\end{array}$ & $\begin{array}{c}\text { Tp-e/0Tc } \geq \mathbf{0 . 2 5} \\
\mathbf{n = 6 7 ( 4 4 . 6 6 \% )}\end{array}$ & $\begin{array}{c}\text { Tp-e/0Tc }<\mathbf{0 . 2 5} \\
\mathbf{n = 8 3}(\mathbf{5 5 . 3 3 \% )}\end{array}$ & $\mathbf{p}$ \\
\hline Arrhythmia & $22(14.6)$ & $12(17.9)$ & $10(11.76)$ & 0.313 \\
\hline Arrhythmia warranting CPR & $6(4)$ & $3(4.4)$ & $3(3.6)$ & 0.789 \\
\hline Death during the procedure & $3(2)$ & $2(2.9)$ & $1(1.2)$ & 0.439 \\
\hline Event during the procedure & $20(13.3)$ & $12(17.9)$ & $8(9.6)$ & 0.138 \\
\hline Type of arrhythmia & & & & 0.148 \\
\hline Atrial fibrillation & $4(2.6)$ & $1(1.4)$ & $3(3.6)$ & $1(1.2)$ \\
\hline Ventricular fibrillation & $4(2.6)$ & $3(4.4)$ & $0(0)$ & $1(1.2)$ \\
\hline Ventricular tachycardia & $2(1.3)$ & $2(2.9)$ & $2(2.4)$ \\
Supraventricular tachycardia & $1(0.6)$ & $0(0)$ & $1(1.2)$ \\
Asystole & $3(2)$ & $1(1.4)$ & $5(7.4)$ & \\
\hline Bradyarrhythmia & $6(4)$ & &
\end{tabular}

CPR: cardiopulmonary resuscitation.

Table 3. Peri-procedural events. Univariate analysis for a Tp-e/0Tc ratio $\geq 0.29$

\begin{tabular}{|l|c|c|c|c|}
\hline Variable & $\begin{array}{c}\text { Total patients } \\
\mathbf{n = 1 5 0}\end{array}$ & $\begin{array}{c}\text { Tp-e/0Tc } \geq \mathbf{0 . 2 9} \\
\mathbf{n = 4 4 ( 2 9 . 3 3 \% )}\end{array}$ & $\begin{array}{c}\text { Tp-e/0Tc }<\mathbf{0 . 2 9} \\
\mathbf{n = 1 0 6}(\mathbf{7 0 . 6 6} \%)\end{array}$ & $\mathbf{p}$ \\
\hline Arrhythmia & $22(14.6)$ & $10(22.7)$ & $12(11.3)$ & 0.720 \\
\hline Arrhythmia warranting CPR & $6(4)$ & $3(6.8)$ & $3(2.8)$ & 0.256 \\
\hline Death during the procedure & $3(2)$ & $2(4.5)$ & $1(0.9)$ & 0.151 \\
\hline Event during the procedure & $20(13.3)$ & $10(22.7)$ & $10(9.4)$ & 0.029 \\
\hline Type of arrhythmia & & & & 0.010 \\
\hline Atrial fibrillation & $4(2.6)$ & $0(0)$ & $4(3.7)$ & $2(1.8)$ \\
\hline Ventricular fibrillation & $4(2.6)$ & $2(4.5)$ & $2(1.8)$ \\
\hline Ventricular tachycardia & $2(1.3)$ & $2(45)$ & $1(0.9)$ \\
\hline Supraventricular tachycardia & $1(0.6)$ & $0(0)$ & $2(1.8)$ \\
Asystole & $3(2)$ & $1(2.2$ & $1(0.9)$ \\
Bradyarrhythmia & $6(4)$ & $5(11.3)$ & & \\
\hline
\end{tabular}

CPR: cardiopulmonary resuscitation.

statistical significance was found for any of the clinical events. However, these results may be related to the retrospective nature of the study since it was not primarily designed to assess mortality.

To analyze the sensitivity and specificity of the Tp-e/ QTc ratio as predictive test for the occurrence of certain events, using receiver operating characteristic (ROC) curves was decided. When in-hospital mortality was assessed by means of ROC curves for the pre-angioplasty Tp-e/QTc ratio, the area under the curve was 0.766 , with a $p<0.044$ (Fig. 3). On the other hand, the post-angioplasty Tp-e/QTc ratio showed an area under the curve of 0.952 , with a $p<0.028$, for the prediction of in-hospital mortality (Fig. 4). No significant area under the curve was observed for other clinical events, and neither for pre-angioplasty TPe/QTc ratio nor post-angioplasty Tp-e/QTc ratio.

\section{Discussion}

Assessing the effect of angioplasty on the Tp-e/QTC ratio in patients with ACIS was decided, since this electrocardiographic parameter represents a relatively constant ventricular repolarization index, with little influence from other variables. From this precept, interest arose in our research group for assessing the effect of a highly prevalent pathology, such as ischemic heart disease, on this TDVR index, and also for assessing 
Table 4. In-hospital events and at 1 year of the acute coronary ischemic syndrome primary event. Univariate analysis for Tp-e/QTc $\geq 0.25$

\begin{tabular}{|c|c|c|c|c|}
\hline Variable & $\begin{array}{c}\text { Total patients } \\
n=147\end{array}$ & $\begin{array}{l}\text { Tp-e/QTc } \geq 0.25 \\
n=54(36.73 \%)\end{array}$ & $\begin{array}{c}\text { Tp-e/0Tc }<0.25 n=93 \\
(63.26 \%)\end{array}$ & p \\
\hline Acute heart failure & $17(11.5)$ & $6(11.1)$ & $11(11.8)$ & 0.896 \\
\hline Cardiogenic shock & $10(6.8)$ & $4(7.4)$ & $6(6.4)$ & 0.824 \\
\hline In-hospital arrhythmia & $23(15.6)$ & 7 (12.9) & $16(17.2)$ & 0.495 \\
\hline In-hospital death & $2(1.3)$ & $2(3.7)$ & $0(0)$ & 0.062 \\
\hline In-hospital event & $30(20.4)$ & $9(16.6)$ & $21(22.5)$ & 0.391 \\
\hline Major cardiovascular event & $6(4.0)$ & $2(3.7)$ & $4(4.3)$ & 0.860 \\
\hline $\begin{array}{l}\text { Type of arrhythmia } \\
\text { Atrial fibrillation } \\
\text { Ventricular fibrillation } \\
\text { Ventricular tachycardia } \\
\text { Supraventricular tachycardia } \\
\text { Asystole } \\
\text { Bradyarrhythmia }\end{array}$ & $\begin{array}{c}7(4.7) \\
0(0) \\
3(2.0) \\
2(1.3) \\
0(0) \\
11(7.4)\end{array}$ & $\begin{array}{c}0(0) \\
0(0) \\
1(1.8) \\
0(0) \\
0(0) \\
5(9.2)\end{array}$ & $\begin{array}{c}7(7.5) \\
0(0) \\
2(2.1) \\
2(2.1) \\
0(0) \\
6(6.4)\end{array}$ & 0.190 \\
\hline Death during $1^{\text {st }}$ year & $1(0.6)$ & $0(0)$ & $1(1.0)$ & 0.131 \\
\hline New ACIS & $29(19.7)$ & $14(25.9)$ & $15(16.1)$ & 0.052 \\
\hline New intervention & $26(17.6)$ & $14(25.9)$ & $12(12.9)$ & 0.019 \\
\hline New event during $1^{\text {st }}$ year & $32(21.7)$ & $17(31.4)$ & $15(16.1)$ & 0.030 \\
\hline
\end{tabular}

ACIS: acute coronary ischemic syndrome.

Table 5. In-hospital events and at 1 year of the acute coronary ischemic syndrome primary event. Univariate analysis for $T p-e / 0 T c \geq 0.25$

\begin{tabular}{|c|c|c|c|c|}
\hline Variable & $\begin{array}{c}\text { Total patients } \\
n=147\end{array}$ & $\begin{array}{l}\text { Tp-e/0Tc } \geq 0.29 \\
n=27(18.37 \%)\end{array}$ & $\begin{array}{c}\text { Tp-e/QTc }<0.29 n= \\
120(81.63 \%)\end{array}$ & p \\
\hline Acute heart failure & $17(11.5)$ & $4(14.8)$ & $13(10.8)$ & 0.559 \\
\hline Cardiogenic shock & $10(6.8)$ & $2(7.4)$ & $8(6.6)$ & 0.890 \\
\hline In-hospital arrhythmia & $23(15.6)$ & $3(11.1)$ & $20(16.6)$ & 0.473 \\
\hline In-hospital death & $2(1.3)$ & $2(7.4)$ & $0(0)$ & 0.003 \\
\hline In-hospital event & $30(20.4)$ & $4(14.8)$ & $26(21.6)$ & 0.425 \\
\hline Major cardiovascular event & $6(4.0)$ & $1(3.7)$ & $5(4.1)$ & 0.913 \\
\hline Death during $1^{\text {st }}$ year & $1(0.6)$ & $0(0)$ & $1(0.8)$ & 0.010 \\
\hline New ACIS & $29(19.7)$ & $7(25.9)$ & $22(18.33)$ & 0.006 \\
\hline New intervention & $26(17.6)$ & $8(29.6)$ & $19(15)$ & 0.002 \\
\hline New event during $1^{\text {st }}$ year & $32(21.7)$ & $10(37.0)$ & $22(18.3)$ & 0.033 \\
\hline $\begin{array}{l}\text { Type of arrhythmia } \\
\text { Atrial fibrillation } \\
\text { Ventricular fibrillation } \\
\text { Ventricular tachycardia } \\
\text { Supraventricular tachycardia } \\
\text { Asystole } \\
\text { Bradyarrhythmia }\end{array}$ & $\begin{array}{c}7(4.7) \\
0(0) \\
3(2.0) \\
2(1.3) \\
0(0) \\
11(7.4)\end{array}$ & $\begin{array}{c}0(0) \\
0(0) \\
1(3.7) \\
0(0) \\
0(0) \\
2(7)\end{array}$ & $\begin{array}{c}7(5.8) \\
0(0) \\
2(1.6) \\
2(1.6) \\
0(0) \\
9(7.5)\end{array}$ & 0.730 \\
\hline
\end{tabular}

SICA: acute coronary ischemic syndrome. 
ROC MedidaRelTpfQTpreBY MuerteIntrahospitalaria(1)

/PLOT=CURVE(REFERENCE)

/PRINT=SE COORDINATES

/CRITERIA=CUTOFF(INCLUDE) TESTPOS(LARGE) DISTRIBUTIONFREE) CI (95)

/MISS ING=EXCLUDE.

ROC curve

Notes

\begin{tabular}{|c|c|c|}
\hline Output created & & 27-SEP-2019 14:23:47 \\
\hline \multicolumn{3}{|l|}{ Comments } \\
\hline \multirow[t]{6}{*}{ Input } & Data & $\begin{array}{l}\text { /Users/rodolforoman/Dr } \\
\text { opbox/DOCUMENTOS } \\
\text { TESIS/BASE DE DATOS } \\
\text { TESIS RODOLFO } \\
\text { ROMAN_01.sav }\end{array}$ \\
\hline & Active dataset & Dataset1 \\
\hline & Filter & $<$ none $>$ \\
\hline & Weighing & $<$ none $>$ \\
\hline & Segment file & $<$ none $>$ \\
\hline & $\begin{array}{l}\text { No. of rows in working } \\
\text { data file }\end{array}$ & 150 \\
\hline \multirow[t]{2}{*}{$\begin{array}{l}\text { Management of lost } \\
\text { values }\end{array}$} & Definition of lost & $\begin{array}{l}\text { User-defined lost values } \\
\text { are treated as missing. }\end{array}$ \\
\hline & Cases used & $\begin{array}{l}\text { Statistics are based on all } \\
\text { cases with valid data for all } \\
\text { variables in the analysis. }\end{array}$ \\
\hline Syntax & & $\begin{array}{l}\text { ROC } \\
\text { MedidaRelTpfQTpre BY } \\
\text { MuerteIntrahospitalaria } \\
\text { (1) } \\
\text { IPLOT=CURVE } \\
\text { (REFERENCE) } \\
\text { IPRINT=SE } \\
\text { COORDINATES } \\
\text { ICRITERIA=CUTOFF } \\
\text { (INCLUDE) TESTPOS } \\
\text { (LARGE) DISTRIBUTION } \\
\text { (FREE) CI(95) } \\
\text { /MISSING=EXCLUDE. }\end{array}$ \\
\hline \multirow[t]{2}{*}{ Resources } & Processor time & $00: 00: 00.25$ \\
\hline & Elapsed time & 00:00:00.00 \\
\hline
\end{tabular}

Figure 3. Pre-angioplasty Tp-e/QTc ratio receiver operating characteristic curve for predicting in-hospital mortality. Area under the curve $=0.766 ; \mathrm{p}<0.044$ (Continued). 


\section{Case processing summary}

Did the patient

die during

hospitalization?

Valid N (by

list)

\begin{tabular}{lr}
\hline Positive $^{\mathrm{a}}$ & 5 \\
\hline Negative & 145 \\
\hline
\end{tabular}

Test result variables larger values

indicate a larger test for a positive

real status.

a. Positive real status is YES.

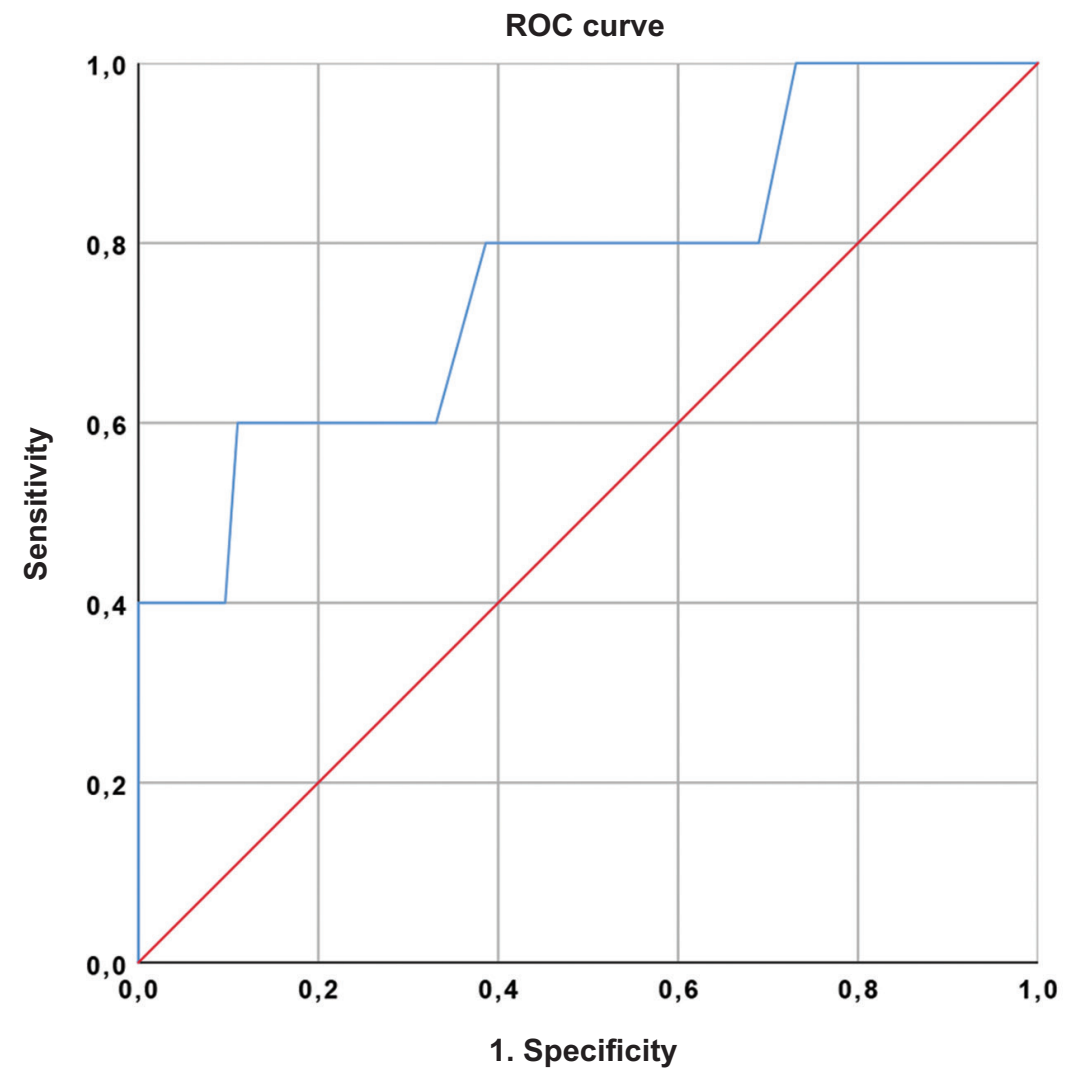

Diagonal segments are generated by ties.

Figure 3. Pre-angioplasty Tp-e/QTc ratio receiver operating characteristic curve for predicting in-hospital mortality. Area under the curve $=0.766 ; \mathrm{p}<0.044$ (Continued). 


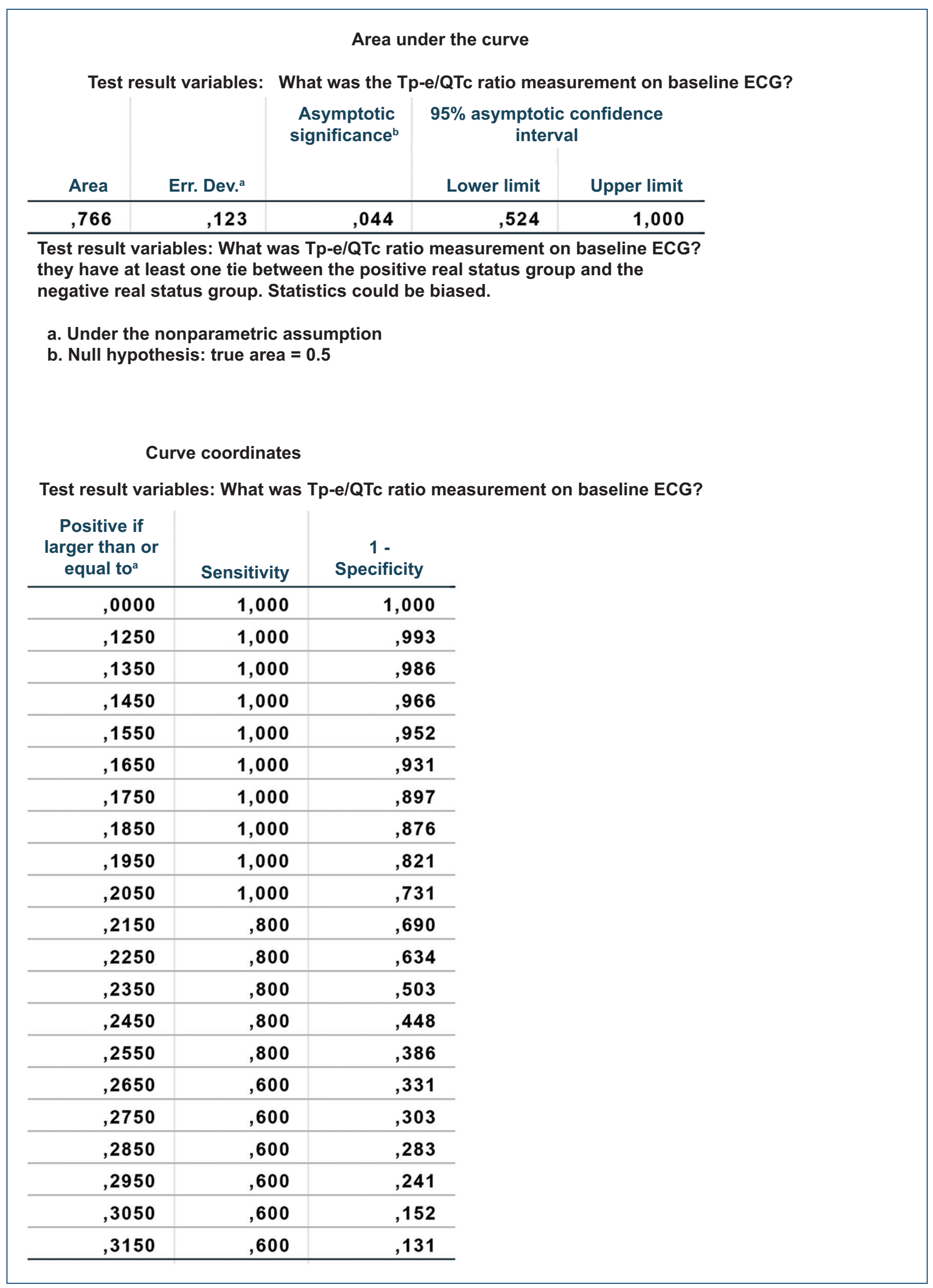

Figure 3. Pre-angioplasty Tp-e/QTc ratio receiver operating characteristic curve for predicting in-hospital mortality. Area under the curve $=0.766 ; \mathrm{p}<0.044$ (Continued). 


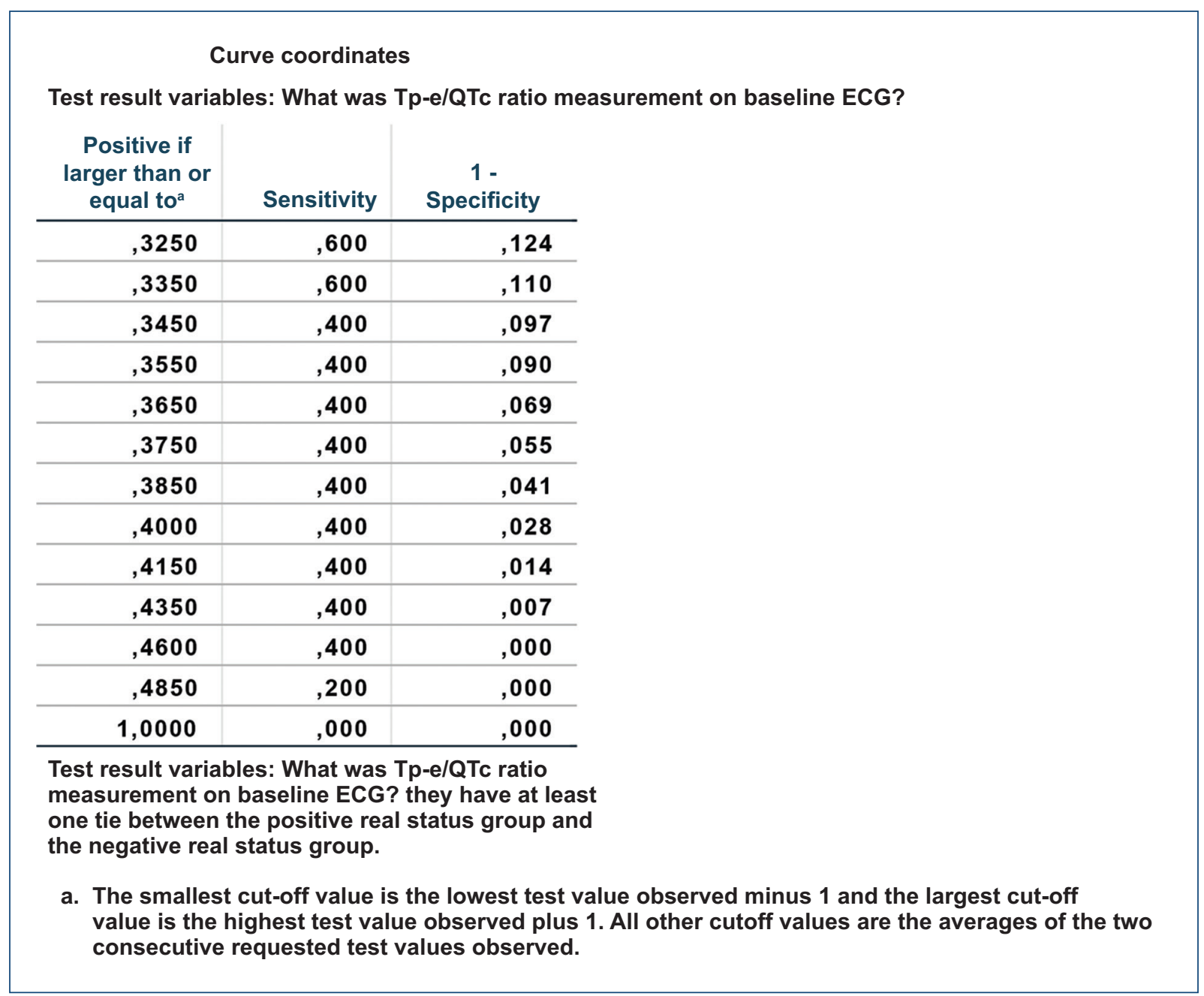

Figure 3. Pre-angioplasty Tp-e/QTc ratio receiver operating characteristic curve for predicting in-hospital mortality. Area under the curve $=0.766 ; \mathrm{p}<0.044$.

the effect of a highly-tested intervention, such as coronary intervention by percutaneous angioplasty, as a prognostic modifier.

Furthermore, knowing about the usefulness of other TDVR measurements as prognostic markers in patients with other pathologies, such as QTC and Tp-e itself, the idea of testing the Tp-e/QTc ratio as a predictive index for the occurrence of cardiovascular events in patients with ischemic heart disease attracted our concerns.

This study provides relevant information on a highly prevalent pathology in our country, and its results are consistent with those of studies in other populations.

It is important to note that the Tec Salud System has a well-established protocol for ACIS care, and this fact provided certain uniformity regarding in-hospital management of the studied patients. In those patients, in whom emergency angioplasty was performed, mean door-to-needle and door-to-balloon times are even lower than that internationally-considered as standard.

Among its limitations, there is the observational and retrospective nature of the study, which confers the inclusion of non-standardized treatment strategies. In addition, the consecutive analysis of events that were subsequent to initial ACIS was based on the review of electronic medical records for follow-up in the outpatient setting, without having a uniform protocol for the monitoring of patients and their treatment subsequent to the primary event.

Measurement of the Tp-e and QT intervals was carried out manually using conventional 12-lead ECG at a recording speed of $25 \mathrm{~mm} / \mathrm{s}$, and this method might have reduced measurement accuracy. 
ROC MedidaRelTpfQTpostBY MuerteIntrahospitalaria(1)

/PLOT=CURVE(REFERENCE)

/PRINT=SE COORDINATES

/CRITERIA=CUTOFF(INCLUDE) TESTPOS(LARGE) DISTRIBUTION(FREE) CI (95)

/MISS ING=EXCLUDE.

ROC curve

Notes

\begin{tabular}{|c|c|c|}
\hline Output created & & 26-SEP-2019 21:13:16 \\
\hline Comments & & \\
\hline Input & Data & $\begin{array}{l}\text { IUsers/rodolforoman/Dr } \\
\text { opbox/DOCUMENTOS } \\
\text { TESIS/BASE DE DATOS } \\
\text { TESIS RODOLFO } \\
\text { ROMAN_01.sav }\end{array}$ \\
\hline & Active dataset & Dataset 1 \\
\hline & Filter & $<$ none> \\
\hline & Weighing & $<$ none $>$ \\
\hline & Segment file & $<$ none $>$ \\
\hline & $\begin{array}{l}\text { No. of rows in working } \\
\text { data file }\end{array}$ & 150 \\
\hline $\begin{array}{l}\text { Management of lost } \\
\text { values }\end{array}$ & Definition of lost & $\begin{array}{l}\text { User-defined lost values } \\
\text { are treated as missing. }\end{array}$ \\
\hline & Cases used & $\begin{array}{l}\text { Statistics are based on all } \\
\text { cases with valid data for all } \\
\text { variables in the analysis }\end{array}$ \\
\hline Syntax & & $\begin{array}{l}\text { ROC } \\
\text { MedidaReITpfQTpost BY } \\
\text { Muertelntrahospitalaria } \\
\text { (1) } \\
\text { /PLOT=CURVE } \\
\text { (REFERENCE) } \\
\text { /PRINT=SE } \\
\text { COORDINATES } \\
\text { ICRITERIA=CUTOFF } \\
\text { (INCLUDE) TESTPOS } \\
\text { (LARGE) DISTRIBUTION } \\
\text { (FREE) CI(95) } \\
\text { /MISSING=EXCLUDE. }\end{array}$ \\
\hline Resources & Processor time & $00: 00: 00.24$ \\
\hline & Elapsed time & $00: 00: 00.00$ \\
\hline
\end{tabular}

Figure 4. Pre-angioplasty Tp-e/0Tc ratio receiver operating characteristic curve for predicting in-hospital mortality. Area under the curve $=0.952 ; \mathrm{p}<0.028$ (Continued). 


\section{Case processing summary}

Did the patient die

during

Valid N (by

hospitalization?

list)

\begin{tabular}{lr}
\hline Positive $^{\mathrm{a}}$ & 2 \\
\hline Negative & 145 \\
\hline Lost & 3 \\
\hline
\end{tabular}

Test result variables larger values indicate a larger test for a real positive status.

a. Real positive status is YES.

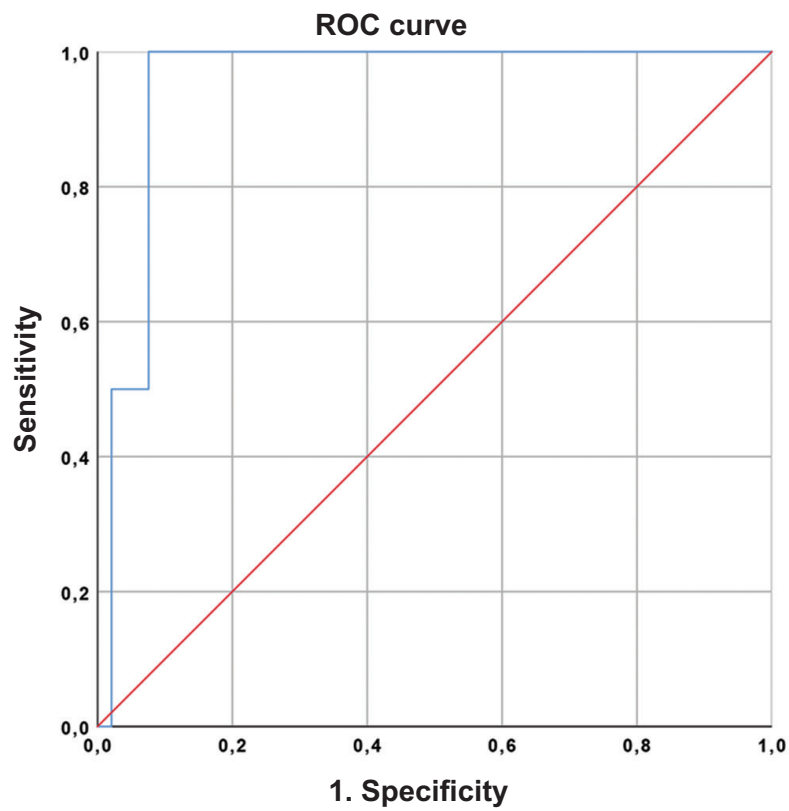

Area under the curve

Test result variables: What was Tp-e/QTc ratio measurement on post-angioplasty ECG?

\begin{tabular}{r|r|r|r|r} 
& & $\begin{array}{r}\text { Asymptotic } \\
\text { significance }^{b}\end{array}$ & $\begin{array}{r}95 \% \text { asymptotic confidence } \\
\text { interval }\end{array}$ \\
Area & Err. Dev. $^{a}$ & & Lower limit & Upper limit \\
\hline, 952 &, 025 &, 028 &, 902 & 1,000 \\
\hline
\end{tabular}

a. Under nonparametric assumption

b. Null hypothesis: true area $=0.5$

Figure 4. Pre-angioplasty Tp-e/OTc ratio receiver operating characteristic curve for predicting in-hospital mortality. Area under the curve $=0.952 ; p<0.028$ (Continued). 


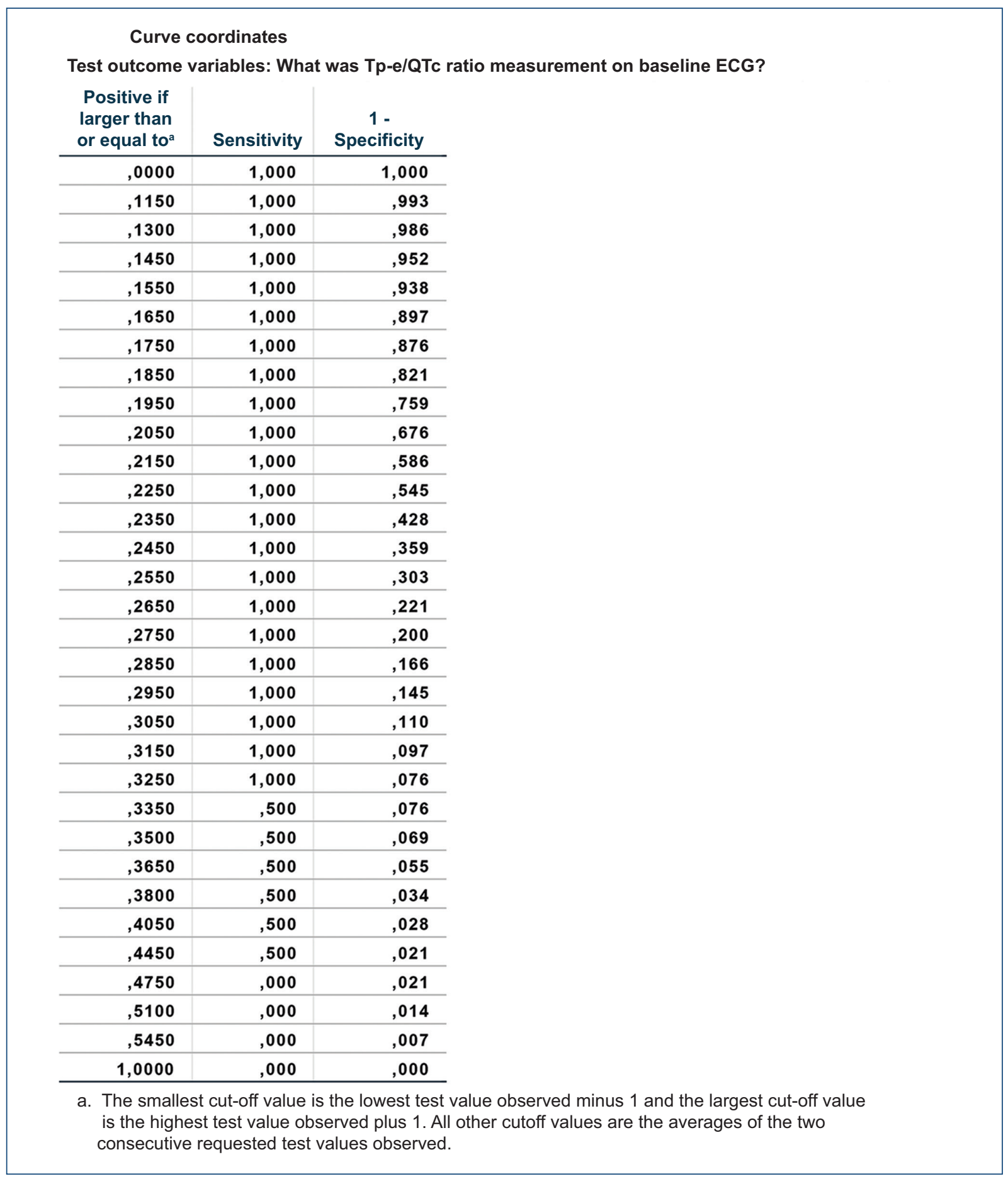

Figure 4. Pre-angioplasty Tp-e/OTc ratio receiver operating characteristic curve for predicting in-hospital mortality. Area under the curve $=0.952 ; p<0.028$.

\section{Conclusions}

After having analyzed the data, it was possible to conclude that there is a significant shortening of the Tp-e/ QTc ratio after angioplasty in patients with ACIS. It is important noting that only when establishing a cutoff point $\geq 0.29$, the pre-angioplasty Tp-e/QTc ratio appears to be related to peri-procedural adverse events overall occurrence. A Tp-e/QTc ratio $\geq 0.25$ after angioplasty has a statistically significant relationship with the 
development of cardiovascular events within the $1^{\text {st }}$ year after the event and with the need for reoperation. A Tp-e/ QTC ratio $\geq 0.29$ after angioplasty has a statistically significant relationship with the occurrence of death after 1 year, the appearance of cardiovascular events within the $1^{\text {st }}$ year and the need for reoperation. This TDVR measurement can serve as a predictor of in-hospital death, cardiovascular events, and reoperation at 1 year in patients with ACIS treated with angioplasty.

\section{Funding}

The authors declare not having received any type funding for the performance of the study.

\section{Conflicts of interest}

The authors declare that they have no conflicts of interest.

\section{Ethical disclosures}

Protection of human and animal subjects. The authors declare that no experiments were performed on humans or animals for this research.

Confidentiality of data. The authors declare that they have followed the protocols of their work center on the publication of patient data.
Right to privacy and informed consent. The authors declare that no patient data appear in this article.

\section{References}

1. Instituto Nacional de Estadística y Geografía. INEGI. Principales causas de mortalidad por residencia habitual, grupos de edad y sexo del falle-cido. (Consultado el 12 de abril de 2018.) Disponible en: http://www.inegi. org.mx/est/contenidos/proyectos/registros/vitales/mortalidad/tabulados/ ConsultaMortalidad.asp.

2. Bayés de Luna A, Coumel P, Leclercq JF. Ambulatory sudden cardiac death: mechanisms of production of fatal arrhythmia on the basis of data from 157 cases. Am Heart J. 1989;117:151-9.

3. Antzelevitch $C$. Cellular basis for the repolarization waves of the ECG Ann N Y Acad Sci. 2006;1080:268-81.

4. Antzelevitch $\mathrm{C}$. Tpeax-Tend interval as an index of transmural dispersion of repolarization. Eur J Clin Invest. 2001;31:555-7.

5. Galinier M, Balanescu S, Fourcade J, Dorobantu M, Boveda S, Mas-sabuau $P$, et al. Prognostic value of ventricular arrhythmias in systemic hypertension. J Hypertens. 1997;15:1779-83.

6. Schwartz PJ, Wolf S. QT interval prolongation as predictor of sudden death in patients with myocardial infarction. Circulation. 1978:57: 1074-77.

7. Sundqvist K, Sylvén C. Cardiac repolarization properties during standar-dized exercise test as studied by QT, QT peak and terminal T-wave in-tervals. Clin Physiol. 1989:9:419-25.

8. Gupta P, Patel C, Patel H, Narayanaswamy S, Malhotra B, Green JT, et al. Tp-e/QT ratio as an index of arrhytmogenesis. J Electrocardiol. 2008:41:1114-6.

9. Erikssen G, Liestøl K, Gullestad L, Haugaa KH, Bendz B, Amlie JP. The terminal part of the QT interval (T peak to $T$ end): a predictor of mortali-ty after acute myocardial infarction. Ann Noninvasive Electrocardiol. 2012;17:85-94.

10. Hetland M, Haugaa KH, Sarvari SI, Erikssen G, Kongsgaard E, Edvardsen T. A novel ECG-index for prediction of ventricular arrhythmias in patients after myocardial infarction. Ann Noninvasive Electrocardiol. 2014;19:330-7.

11. Zhao X, Xie Z, Chu Y, Yang L, Xu W, Yang X, et al. Association between Tp-e/QT ratio and prognosis in patients undergoing percutaneous coro-nary intervention for ST-segment elevation myocardial infarction. Clin Cardiol. 2012;35:559-64. 